\title{
DEMOCRATIZAÇÃO, QUALIDADE E CRISE DA EDUCAÇÃO SUPERIOR: FACES DA EXCLUSÃO E LIMITES DA INCLUSÃO*
}

JOSÉ DiAS SOBRINHO

\begin{abstract}
RESUMO: O artigo trata de aspectos da "democratização" na educação superior brasileira. Discute contradiçōes entre concepções de educação como bem público-social e como mercadoria, relacionando-as com as políticas públicas desse nível de ensino. Tematiza as noções de qualidade e de pertinência social. Afirma que as políticas públicas de democratização da educação superior devem ir muito além das ações focadas no aumento de matrículas e de inclusão social. A democratização requer melhorar e ampliar a educação fundamental, de modo a elevar a quantidade e a qualidade de concluintes no ensino médio; ampliar e melhorar continuamente a formação de professores e a infraestrutura de todo o sistema educativo; assegurar boas condiçôes de permanência do estudante nos cursos; ampliar a participação do Estado no provimento da educação. Em conclusão: transformações radicais na educação superior, especialmente a sua expansão com qualidade e equidade, não se separam de mudanças estruturais e sustentáveis da sociedade.
\end{abstract}

Palavras-chave: Educação superior. Democratização. Qualidade. Políticas públicas. Inclusão social.

* $\quad$ Este texto foi especialmente escrito para o II Seminário de Educação Brasileira: "Os desafios contemporâneos para a educação brasileira e os processos de regulação", realizado pelo Centro de Estudos Educação e Sociedade (CEDES) na Universidade Estadual de Campinas (UNICAMP), de $1^{\circ}$ a 3 de dezembro de 2009.

** Doutor em Educação e professor titular do Programa de Pós-Graduação em Educação da Universidade de Sorocaba (UNISO).E-mail: jose.sobrinho@prof.uniso.br

Educ. Soc., Campinas, v. 31, n. 113, p. 1223-1245, out.-dez. 2010

Disponível em <http://www.cedes.unicamp.br> 
Democratização, qualidade e crise da educação superior...

\title{
DEMOCRATIZATION, QUALITY AND HIGHER EDUCATION CRISIS: FACES OF EXCLUSION AND LIMITS OF INCLUSION
}

\begin{abstract}
This paper deals with aspects of the "democratization" of higher education in Brazil. It discusses the contradictions between conceptions of education as a public good and as a commodity, and relates them to higher education public policies. It approaches the notion of quality and social relevance and asserts that public policies oriented towards the democratization of higher education must go far beyond the actions focused on the increase of enrollment and social inclusion. Democratization requires an improvement and expansion of elementary education in order to enhance the quantity and quality of high school graduates, and continuously improve and widen teachers' education and the infrastructure of the whole educational system. It also demands good conditions so that students do not quit their courses and an increased participation of the State as an education provider. In conclusion: radical changes in higher education, particularly its expansion with quality and equity, are not separated from structural and sustainable modifications in the society.
\end{abstract}

Key words: Higher education. Democratization. Quality. Public policies. Social inclusion.

\section{Introdução}

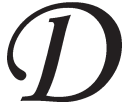

emocratização, qualidade e crise são núcleos temáticos que ocupam o centro da agenda da educação superior em todo o mundo. Antes de tratar especificamente desses temas, devo invocar um princípio fundamental que fornece as bases e os sentidos, isto é, significados e direções, das reflexões que vão se seguir. Refirome ao princípio da educação como bem público, direito social e dever do Estado. De pronto, esse princípio rechaça a ideia de educação como mercadoria e todos os processos mercantilistas que vêm ganhando força e amplitude nas últimas décadas. Uma educaçãomercadoria não poderia ser democrática, pois só seria acessível àqueles que a podem comprar. Num país cuja maioria da população é pobre, como o Brasil, a população de baixa renda poderia pagar, na melhor das hipóteses, por uma educação-mercadoria de baixo custo e precária qualidade. A educação-mercadoria tem compromisso com o lucro do empresário que a vende. A educação-bem público tem compromisso com a sociedade e a nação. 
É a partir desse princípio que faz sentido falar de democratização do acesso e garantia de permanência dos estudantes em cursos superiores com qualidade científica e social. $\mathrm{O}$ direito social à educação de qualidade é um aspecto essencial e prioritário da construção da sociedade, de consolidação da identidade nacional e instrumento de inclusão socioeconômica. Por isso, assegurá-lo adequadamente é dever indeclinável do Estado.

Quando não compreendida como bem público, a educação atende prioritariamente ao indivíduo e a seus interesses exclusivos. Neste caso, a qualidade estará determinada por significados marcadamente operacionais e instrumentais, muito mais que sociais e voltados ao bem comum. Um princípio defendido neste texto explicita que a qualidade deve ser para todos e ser imprescindível à construção de sujeitos sociais, e não somente para parcela privilegiada da sociedade e para o fortalecimento do individualismo.

A qualidade tem uma irrecusável dimensão social e pública. $\mathrm{O}$ correlativo da ideia de educação como um bem público e direito social é o dever do Estado de garantir amplas possibilidades de oferta de educação de qualidade a todas as camadas sociais (Dias Sobrinho, 2009). Certamente, é justificável refletir um pouco sobre esse conceito de qualidade aplicado à educação superior.

Outra passagem explicativa obrigatória, que será discutida mais adiante, consiste numa visão compreensiva das transformações da educação superior como aspecto do cenário geral de metamorfoses da sociedade, da economia, do mundo do trabalho e, particularmente, do conhecimento. Muito do que se atribui à educação superior como sendo sua crise é, na realidade, um fenômeno muito mais amplo que, simplificando, chamaríamos de crise da sociedade da economia global. Por isso, importantes problemas da educação não serão resolvidos no interior das instituiçôes e dos sistemas educativos. São problemas que conformam a crise geral dos nossos tempos, constituída, entre outros aspectos, pela perda de referências de valor, explosão da informação e dos conhecimentos, rápida obsolescência dos produtos, mudanças nos perfis profissionais, obsessão consumista, individualismo, incertezas quanto ao futuro, economia como princípio regulador da sociedade etc.

Por outro lado, a comunidade acadêmico-científica também é um importante ator nas transformações do mundo. A crise da educação 
Democratização, qualidade e crise da educação superior...

superior é parte da crise estrutural. A educação superior pode contribuir para a solução de muitos problemas, mas também para a permanência de outros. A crise que enfocaremos aqui mais amiúde diz respeito a uma crise do sentido público, ligada à crise do princípio da equidade e à conceituação da qualidade da educação superior. Esses núcleos temáticos remetem, necessariamente, às questóes da democratização, da desigualdade, da exclusão e da inclusão social.

É necessário esclarecer desde logo que a "democratização" da educação superior não se limita à ampliação de oportunidades de acesso e criação de mais vagas. Além da expansão das matrículas e da inclusão social de jovens tradicionalmente desassistidos, em razão de suas condições econômicas, preconceitos e outros fatores, é imprescindível que lhes sejam assegurados também os meios de permanência sustentável, isto é, as condiçõos adequadas para realizarem com boa qualidade os seus estudos. Assim, acesso e permanência são aspectos essenciais do processo mais amplo de "democratização". Porém, a expansão quantitativa é só uma das faces da questão da "democratização" da educação superior, como veremos principalmente ao tratarmos dos temas do valor público, da qualidade social e da pertinência.

Essas premissas levam a outra: a educação deve ser vista e organizada como um sistema articulado. Vale dizer que o tempo da educação é um tempo total, permanente, contínuo, pois a formação humana é um processo jamais concluído. O inacabamento é da essência humana, ainda que o discurso social tenda a impingi-lo às classes sociais de baixa renda, fazendo crer que os pobres são imperfeitos, em oposição a uma falsa e ilusória completude dos indivíduos pertencentes aos segmentos ricos e poderosos.

As diversas etapas de escolarização formal organizam os processos de formação que farão parte da vida toda de uma pessoa. A exclusão escolar, em qualquer etapa, é privação de algumas bases cognitivas, sociais e axiológicas que todo indivíduo necessita para edificar uma existência humanamente significativa na sociedade contemporânea.

\section{Qualidade técnica e social da educação superior}

No atual quadro de hegemonia da globalização da economia capitalista e sua ideologia, predomina a tendência de entender e a todos 
fazer crer que uma educação tem tanto mais qualidade quanto mais propicia aos indivíduos e às empresas maiores ganhos de eficiência e de capacidades competitivas. Em outras palavras, a qualidade educativa estaria associada à produtividade, lucro, desenvolvimento a qualquer custo, empreendedorismo, competitividade, competências profissionais apropriadas às mudanças no mundo do trabalho e na economia. Ela seria subsidiária da racionalidade empresarial, em que prevalecem o individual sobre o comunitário, o privado sobre o público, os interesses e concepções instrumentais sobre os valores da vida social. Educação de qualidade seria, na perspectiva neoliberal, a que equipa o indivíduo com conhecimentos e técnicas úteis à démarche competitiva individual e ao fortalecimento das empresas, numa lógica em que esse mecanismo é entendido como o mais importante motor do enriquecimento e progresso de um país.

Os mecanismos ideológicos agem intensamente no campo da educação e suas relações com o Estado, pois esse é um campo de alto significado para a propagação e hegemonia do capitalismo em sua atual versão neoliberal. O discurso e as práticas dos operadores dos Estados estão recheados de ideias e promessas de desenvolvimento a ser alcançado por meio da gestão eficiente do sistema educacional. Nas políticas setoriais públicas, as preocupações centrais consistem na organização de sistemas de informação e de controle através da elaboração e execução de um forte aparato legal-normativo, sempre acompanhado de processos de regulação, avaliação e acreditação. $\mathrm{Na}$ agenda brasileira de educação superior aparece, com grande relevo, a questão da ampliação das matrículas e o controle das aprendizagens estudantis exercido por meio de exames de larga escala. São medidas socialmente valorizadas e de grande apelo político, especialmente quando publicam informações quantitativas. Do ponto de vista dos responsáveis por essas políticas oficiais, a qualidade que vige nesses instrumentos e programas e deles resulta se considera tecnicamente legitimada pela objetividade de suas medidas, quantificações e procedimentos metodológicos e eticamente justificada ao se tornar transparente à população em geral e aos potenciais "clientes".

Em torno da hegemonia do conceito de qualidade ocorrem muitos conflitos e oposiçôes entre os diferentes grupos de interesse. Cada grupo e, no limite, cada indivíduo prioriza em cada momento uma ou 
Democratização, qualidade e crise da educação superior...

algumas características da qualidade educativa e não considera a sua complexidade semântica. De acordo com interesses relativos dos implicados em determinadas circunstâncias e admitindo sempre variaçôes de ênfases, a qualidade estaria: na adequada capacitação para o trabalho e expansão de possibilidades de emprego; ou no aumento da competitividade por meio dos conhecimentos úteis, da inovação e do avanço da tecnologia; ou na elevação da formação cultural e política da população; ou no aprofundamento dos valores da democracia e no desenvolvimento da cidadania etc. Tudo isso e mais constitui a pluralidade conceitual da qualidade educativa, mas dificilmente esses elementos se articulam de forma harmoniosa em um todo compreensivo, visto que a educação é um fenômeno social e, então, o que se vai entender por qualidade educativa pertence a um campo complexo e permeado de contradiçóes (Dias Sobrinho, 2008).

A qualidade da educação superior não pode ser pensada fora das ações e dos compromissos que cada instituição instaura em seu âmbito interno e em suas vinculações com o entorno mais próximo, com a sociedade nacional, os contextos internacionais do conhecimento e o Estado nacional. Por isso, são inaceitáveis as formulações da educação como bem público global propostas por influentes organismos multilaterais, capitaneados pelo Banco Mundial com adesão de alguns setores da UNESCO. Mais ainda inadmissível é a tentativa de alguns países ricos de oficializar a educação como um bem comercializável a ser controlado pela Organização Mundial do Comércio (OMC). Essas duas formulações interessam aos países industrialmente mais avançados, mas não correspondem às necessidades e projetos dos países pobres e em desenvolvimento.

Instituições e Estado são constituídos e construídos por seres humanos e carregam as contradições sociais e os diferentes projetos existenciais e coletivos. Uma formação social é constituída por uma amálgama de expectativas de futuro, interesses e projetos particulares e corporativos, concepçóes de desenvolvimento social e econômico, oportunidades de emprego e de promoção social, necessidades existenciais, sonhos etc. As noções de qualidade da educação superior têm muito a ver com os lugares relativos dos indivíduos, os compromissos dos grupos numa dada formação social, as concepções de mundo e, particularmente, os papéis que os atores atribuem à educação superior. Dada 
a heterogeneidade das concepções de mundo e tendo em vista as contradições de toda formação social, dificilmente se construirá unanimidade a respeito do que é e deve ser uma educação superior de qualidade.

\section{Exclusão e inclusão sociais}

Uma sociedade que produz excluídos pela pobreza, violência, racismo, analfabetismo, desídia relativamente à saúde, educação, segurança, habitação e demais condições de vida digna é uma sociedade partida, conflituosa, intolerante, preconceituosa e injusta. Exclusão gera marginalização, ignorância, insegurança, violência, ruptura do tecido social.

A pobreza é, possivelmente, o mais importante fator de exclusão social e cultural. Privação dos bens materiais e exclusão dos bens espirituais e culturais têm sempre uma forte correlação. Entretanto, podem apresentar distintos matizes. Na população brasileira, o passivo educacional é ainda maior que o econômico, embora esses déficits também se interajam. É ainda muito pequena a parcela da grande massa dos pobres brasileiros que consegue fazer um longo e bom percurso escolar. Segundo a Pesquisa Nacional por Amostragem de Domicílios (PNAD), de 2007, realizada pelo Instituto Brasileiro de Geografia e Estatísticas (IBGE), menos de 3\% dos estudantes de educação superior pertencem ao quinto mais pobre, ao qual pertencem $30,2 \%$ das famílias brasileiras.

O conhecimento é indispensável para a realização pessoal, para o exercício profissional, o fortalecimento econômico e o desenvolvimento da nação. Equidade é um valor cuja aplicação tende a diminuir as igualdades sociais. Todo Estado democrático haveria de promover esforços, juntamente com a sociedade, para interromper o círculo vicioso da desigualdade socioeducativa. No horizonte ético da equidade estão a ampla e qualificada escolarização geral e a consolidação de uma sociedade justa e igualitária. Entretanto, uma sociedade que construiu profundas assimetrias durante séculos não consegue realizar, em plenitude e em pouco tempo, esses propósitos. Mas é preciso começar priorizando algum foco que traga resultados mais rápidos. Por equidade, faz sentido empreender ações específicas em prol do atendimento das camadas 
Democratização, qualidade e crise da educação superior...

mais pobres, sem postergar as ações mais amplas e radicais de caráter sustentável e estrutural.

A exclusão educacional é um fenômeno que apresenta múltiplos problemas, que vão desde o analfabetismo, as evasões, a repetência, as carências econômicas e culturais familiares, os preconceitos, a falta de vagas, a escassa formação de parte dos professores, as precárias condiçôes de escolarização de muitos jovens, até a falta de perspectivas de futuros bons empregos.

Polarizada em camadas sociais antagônicas, a sociedade escolhe os valores e interesses dos mais ricos como referência valorativa central para toda população. Dessa forma, se naturalizam as desigualdades e assimetrias sociais e se definem os espaços "naturais" de cada um. Como corolário da exclusão produzida pela sociedade e pelo Estado, sobrevém a autoexclusão: os jovens excluídos dos bens comuns acabam, muitas vezes, internalizando, ao longo de suas trajetórias estudantis, a ideologia de que a exclusão é natural e de que é natural que eles se incluam entre os excluídos sociais. Interiorizam que, na melhor hipótese, teriam capacidades intelectuais e econômicas e, eventualmente, algum direito de frequentarem tão somente os cursos mais acessíveis, menos seletivos e de baixo prestígio, aqueles que lhes abririam mais possibilidades de aprovação, embora sem nenhuma garantia de que venham a alcançar os empregos mais valorizados.

Não é só o fato de levarem desvantagens em suas formações anteriores, aí incluídas as debilidades de ensino-aprendizagem e as precárias informaçóes a respeito do que seria uma vida universitária rica e potencialmente importante para os seus futuros de cidadãos e profissionais. É toda uma mentalidade de excluídos da vida que vai consolidando a ideia de que os diferentes graus da exclusão da educação superior e as baixas capacidades competitivas são "naturais", da mesma forma que as desigualdades formam parte "naturalmente" da sociedade. É importante assumir esse tipo de exclusão que não se mostra nas estatísticas mais simples: a exclusão por dentro do sistema, cujas faces são a oferta de ensino de baixa qualidade e a autoexclusão.

Os números da exclusão educacional no Brasil mostram uma realidade perversa. Na América Latina, até mesmo países muito mais pobres apresentam taxas de escolarização superiores às nossas. A matrícula em educação superior no Brasil está abaixo da média latino- 
americana: apenas 13\% dos jovens na faixa etária adequada (18-24 anos) frequentam algum curso superior. Também em relação ao ensino médio completo, os brasileiros alcançam resultados inferiores a muitos dos nossos vizinhos. Nem é necessário apresentar outros números, de resto sobejamente divulgados, para admitir a amplidão e a gravidade das assimetrias sociais brasileiras.

A sociedade democrática é fundada no princípio ético da equidade e, portanto, deve assegurar o direito de todos à educação de qualidade. Uma educação precária jamais poderá ser considerada satisfatória. Porém, uma educação de baixa qualidade, mesmo que insatisfatória, ainda é melhor que nenhuma, pois, de alguma forma, colabora para elevar o patrimônio coletivo de conhecimentos e competências profissionais de uma nação. Em que pese não ser nula de valor e até contribuir para uma melhora de indicadores sociais, a educação de baixa qualidade está longe de poder resolver os problemas de justiça social, pois a maioria dos estudantes das escolas de pífios desempenhos fica em condições desvantajosas em relação àqueles de estratos sociais mais bem aquinhoados. Estes podem mais facilmente construir um itinerário educativo compatível com as demandas de alta competitividade que a sociedade de economia global está a exigir.

Um sistema educativo que reforça os preconceitos e amplia a marginalização social não pode ser de qualidade, do ponto de vista dos princípios de bem público e equidade. Uma sociedade que nega a oferta de educação de qualidade para todos é uma sociedade injusta e democraticamente pouco desenvolvida. A educação de qualidade reservada a uma pequena elite pode interessar a alguns aspectos do mercado mais exigente e que requer tecnologias de ponta e conhecimentos de refinado desenvolvimento, mas não ajuda a promover a justiça social.

A questão da "democratização" da educação superior adquiriu fôlego nestas últimas décadas e entrou fortemente na agenda das políticas públicas. Ela já era considerada importante, desde os meados do século passado, pela teoria do capital humano e pela teoria residual do desenvolvimento econômico. Segundo essas teorias, o desenvolvimento econômico requer grandes investimentos em educação. De modo mais efetivo, propunham as políticas de expansão da escolaridade da população em geral (Neave, 2001, p. 13-14). Embora 
Democratização, qualidade e crise da educação superior...

apresente o mérito de reconhecer a importância da ampliação da escolaridade e das inversões na educação, essa agenda não esconde seus fundamentos marcadamente economicistas, segundo os quais a educação se restringe a ser uma função da economia.

\section{Expansão das matrículas, acesso e permanência}

As políticas de expansão da escolaridade e, particularmente, de ampliação das matrículas na educação superior constituem aspectos que deveriam ser considerados importantes não simplesmente do ponto de vista dos interesses econômicos, mas, sobretudo, da democratização da sociedade e do aprofundamento da justiça social. Porém, com relação à educação superior, é importante observar que as políticas de expansão do acesso só se efetivarão plenamente no caso de haver existido uma cobertura completa e com qualidade nos níveis educacionais precedentes, a começar pela pré-escola. Essas políticas requerem ações de grandes proporções e de elevados custos. No Brasil, a ampliação e a melhoria do sistema de educação, em termos quantitativos e qualitativos, requerem investimentos públicos prioritariamente em, ao menos, duas áreas: é necessário empreender uma grande expansão da infraestrutura física das escolas de nível básico e, ao mesmo tempo, impulsionar vigorosamente a formação de mais e mais bem preparados professores.

A educação é fundamental para o desenvolvimento das chamadas sociedades da informação e do conhecimento. Quem não domina o alfabeto digital - em geral, os mais pobres - sofre enormes desvantagens na sociedade de economia global. Competência na linguagem que modela e move a economia global é o grande diferencial entre pobres e ricos, sejam países ou indivíduos. Os analfabetos digitais tendem a se tornar cada vez mais descartáveis. Diminuir os impactos da exclusão digital, que é um componente da exclusão em geral, deveria ser um aspecto importante da agenda atual da educação e, obviamente, do Estado (Dias Sobrinho, 2005).

No Brasil, há microcomputador em 32,2\% das residências, mas sua distribuição é francamente desigual: possuem microcomputador somente $25,8 \%$ dos domicílios cujos moradores têm renda de até 10 salários mínimos, contra $92,9 \%$ das moradias cujos residentes 
acumulam rendimentos mensais acima de 20 salários mínimos. A exclusão digital é uma das expressões da exclusão geral, participando, a seu modo, como causa e consequência. Por outro lado, quanto mais alguns segmentos sociais se beneficiam dos meios de informação eletrônicos, especialmente da internet, mais obtêm vantagens competitivas, principalmente pela facilidade de muito rapidamente se apropriarem de conhecimentos e informações. O fosso entre incluídos e excluídos digitais tende a aumentar, caso não haja políticas consistentes de investimentos e formação nessa área.

\section{Políticas públicas de ampliação de vagas e inclusão social}

Significativos segmentos da população vêm conseguindo alguma ascensão de categoria social, nos anos mais recentes, mas as desigualdades continuam tendo grandes proporções. Segundo a PNAD/ 2008, 43\% da riqueza brasileira são apropriados pelos $10 \%$ mais ricos, enquanto que $18 \%$ se distribuem entre os $50 \%$ mais pobres. A diferença entre os $10 \%$ mais ricos e os $10 \%$ mais pobres no Brasil é das maiores do mundo. Dos 190 milhōes de brasileiros, cerca de 60\% recebem, em média, 455 reais. Mais de $85 \%$ da população nordestina não ganham sequer um salário mínimo.

Pobreza e precária ou mesmo nenhuma escolaridade não se separam. A pirâmide educacional é um elemento do quadro geral das assimetrias sociais. Os brasileiros mais pobres não chegam a completar nem mesmo cinco anos de escolaridade, enquanto os mais ricos ultrapassam a marca de dez anos. Em média, os brasileiros não completam nem mesmo sete anos de escolaridade, isto é, não concluem sequer a educação básica. No nordeste, a escolaridade é ainda menor: somente um em cinco completa a educação básica. Neste ano (2009), $87 \%$ dos jovens de idade adequada (18-24 anos) estão fora do ensino superior. Os 13\% matriculados estão muito longe dos 30\% que, em 2000, o Plano Nacional da Educação estabelecia como meta a ser atingida até 2010. Ainda há mais de 14 milhões de analfabetos adultos, com mais de 25 anos. Esses poucos números são suficientes para mostrar a precariedade do sistema educacional brasileiro. Dado o baixo poder aquisitivo da maioria da população, é indispensável que a expansão se dê mais intensamente pelo sistema público. 
Democratização, qualidade e crise da educação superior...

A globalização econômica neoliberal produziu um deslocamento da referência central da universidade: das humanidades para as disciplinas técnicas. Se antes o conhecimento universal produzido na universidade era centrado nas humanidades, agora a economia globalizada fez prevalecer o universalismo de base técnica. As disciplinas "ricas" e que apresentam as mais altas vantagens competitivas nas disputas por financiamentos e prestígios são definidas, em grande parte, nas esferas acadêmicas de grande reconhecimento universal e vinculadas aos interesses das grandes empresas e laboratórios transnacionais e, ainda, legitimadas pelos atores nacionais. Nessa relação entre notáveis pesquisadores, grandes empresas e atores dos Estados se estabelecem os temas prioritários de pesquisa e os critérios de produção e avaliação do conhecimento "útil".

A economia globalizada é movida em grande parte pelo conhecimento, especialmente pelo conhecimento aplicável e útil para as empresas. É importante para essa economia que amplos setores da população, em diferentes níveis, se apropriem dos conhecimentos aplicáveis para aumentar a base de produção e de consumo dos produtos industriais. Também do ponto de vista da economia globalizada, tornou-se necessário aumentar consideravelmente as oportunidades e os tempos de estudo, sobretudo para os jovens provenientes de famílias de baixa renda. Perversamente, os que não conseguem produzir e consumir, por pobreza e/ou incapacidade intelectual, são descartados, assim como os produtos obsoletos e imperfeitos.

Muitos países ricos têm aumentado seus investimentos públicos na educação. Entretanto, países pobres ou em desenvolvimento tendem a facilitar a expansão do setor privado como forma de atender a crescente demanda por educação. A expansão de matrículas está no centro das políticas de democratização da educação superior. Mas há também medidas que visam a ampliar a inclusão social, sem necessariamente criar novas vagas. É este o caso de algumas açôes impulsionadas no âmbito do que se convencionou chamar, genericamente, de "ações afirmativas" ou de "discriminação positiva".

Entre as principais iniciativas de ações afirmativas que o MEC brasileiro vem impulsionando, as mais polêmicas são as cotas, que dão atenção especial a estudantes pobres, notadamente a afrodescendentes e indígenas, jovens oriundos de escolas públicas e portadores 
de necessidades especiais (Dias Sobrinho, 2006). Conhecer o cenário das transformações que vêm ocorrendo na educação superior brasileira ajuda a entender por que se tornou necessário promover políticas públicas de ampliação de vagas, inserção social e diminuição das desigualdades. Seguem algumas poucas indicações a esse respeito.

A partir de 1970, acelerando-se nos últimos 15 anos, ocorreu no Brasil e em muitos outros países uma notável expansão do sistema educacional superior, principalmente pela via privada. Em 1970, havia 425.478 estudantes nos cursos superiores, cerca de $51 \%$ deles em instituições privadas. Em 2009, são privadas cerca de $90 \%$ das 2.252 instituiçôes e $74,9 \%$ das 5.080 .056 matrículas. Enquanto no setor privado predomina a oferta de vagas no período noturno $(70 \%)$, nas instituições públicas $62,5 \%$ das matrículas estão nos períodos diurnos. Nesta década de 2000 , as matrículas privadas cresceram $100 \%$, contra os $40 \%$ do setor público. Nos cursos de pós-graduação, essa lógica não prevalece, pois a maioria dos 141.664 estudantes de mestrado (91.996) e de doutorado (49.638) está matriculada em instituições públicas.

Há 1.479 .318 vagas não preenchidas, $98 \%$ delas no setor privado. Essa grande quantidade de vagas privadas aponta para uma tendência de saturação da demanda outrora reprimida e, o que é muito grave, para a incapacidade de uma boa parcela de jovens, que se calcula em volta de $25 \%$, para pagar mensalidades e assegurar sua permanência no curso, até mesmo se esse lhes fosse gratuito. Entre as principais causas da evasão, superior a $25 \%$ no segmento privado, certamente se incluem as carências econômicas. A ociosidade e a evasão indicam que há uma grande disponibilidade de vagas no setor privado. Dadas as severas restriçóes econômicas das classes pobres, essas vagas acabariam não sendo ocupadas, a não ser por políticas públicas. Daí o evidente interesse dessas instituições em disputar as matrículas de beneficiários de políticas públicas.

As políticas de ações afirmativas têm particular interesse para a população afrodescendente. Como se sabe, ainda que nos anos mais recentes se possa observar alguns indicativos mais favoráveis, esse grupo social é o que sofre os mais perversos tipos de exclusão. Quase a metade da população brasileira é formada por pretos e pardos. Entretanto, são afrodescendentes apenas 25,4\% dos estudantes 
Democratização, qualidade e crise da educação superior...

de cursos superiores da coorte 18-24, sendo que menos de 3\% dos pretos frequentam uma instituição de educação superior.

O Programa Universidade para Todos (PROUNI) facilita a ocupação de vagas a estudantes de baixa renda em instituiçôes privadas, por meio de financiamento público (Dias Sobrinho \& Brito, 2008). O Programa contabiliza cerca de 400 mil bolsistas ativos. Ele tem sido um programa valiosíssimo para milhares de jovens que estariam excluídos da educação superior por falta de recursos próprios de financiamento.

Porém, há limites e problemas nesse programa. Como se sabe, as instituiçóes de ensino superior (IES) privadas, especialmente as de pequeno porte e de recente criação, em sua maioria, não têm em alto valor a investigação sistemática e tampouco se ocupam da formação de pesquisadores. Por isso, os estudantes incluídos no PROUNI dificilmente terão algum benefício dos resultados da pesquisa na estrutura curricular e tampouco receberão formação em pesquisa, especialmente nas áreas "ricas". Isso poderá ter impactos muito negativos nas competiçóes no mundo do trabalho e na sociedade.

As argumentações anteriores sugerem que é social, política e economicamente imprescindível que o Estado expanda consideravelmente o sistema público, ampliando matrículas especialmente naquelas instituições que têm estruturas e experiências consolidadas em pesquisa e formação de professores e de pesquisadores.

É justo reconhecer as iniciativas que o governo brasileiro vem empreendendo para expandir o setor público federal, seja pela criação de novas instituições e extensão de campi fora da sede, pela implantação de cursos tecnológicos, seja pela criação de vagas prioritariamente para estudantes de baixa renda, especialmente os afrodescendentes e oriundos da rede pública. Neste último caso se inclui o Plano de Reestruturação e Expansão das Universidades Federais (REUNI).

O REUNI começa a ser adotado em muitas universidades federais. Utiliza, basicamente, a seguinte fórmula: a universidade elabora um projeto de desenvolvimento institucional, recebe os recursos do MEC e amplia as vagas de acordo com os critérios aprovados. Entre os objetivos que orientam o programa, segundo o Decreto n. 6.096/2007, que o instituiu, citam-se: redução das taxas de evasão, aproveitamento de vagas ociosas, otimização da mobilidade estudantil, 
reorganização curricular, diversificação da oferta de cursos de graduação, ampliação de políticas de inclusão e assistência aos estudantes, articulação entre os diversos níveis de educação.

Diferentes modalidades de ações afirmativas, entre as quais se incluem os sistemas de cotas sociais e raciais e de acréscimo de bônus no exame de ingresso, têm sido adotadas por universidades públicas com a finalidade de incluir jovens pertencentes a grupos étnicos tradicionalmente desfavorecidos, notadamente os afrodescendentes. As cotas e bônus não necessariamente expandem a quantidade de vagas. Seu propósito maior é promover a inclusão social de alguns grupos marginalizados. Além do mérito da inclusão, muitas vezes essas políticas acabam colaborando para o desenvolvimento de algumas regiôes periféricas.

\section{Limites e problemas das políticas setoriais}

Por mais benéficas e necessárias que sejam, as políticas de "democratização" da educação superior, por via de ampliação de matrículas e açôes afirmativas de inclusão social, apresentam sérios limites que não serão transpostos em curto espaço de tempo. Muito positivo é o fato de que elas contribuem para uma mudança de cultura contrária à permanência perversa do elitismo e do racismo e favorável ao abrandamento das assimetrias sociais. O principal obstáculo para a "democratização" e expansão da educação superior é a vulnerabilidade de grande parte da população brasileira.

A pobreza tem estreita relação com a precariedade educacional da educação básica. Nem $40 \%$ dos jovens brasileiros completam o ensino médio. Há menos concluintes do ensino médio que vagas no ensino superior. Entretanto, dados levantados pelo IBGE permitem afirmar que cerca de um quarto dos jovens em idade adequada não teria condiçôes econômicas para frequentar um curso superior, ainda que gratuitamente. Isso posto, pode-se concluir que os programas focados na ampliação de vagas e as ações de discriminação positiva, dirigidas à inclusão social, são importantes, porém insuficientes e encontram sérios limites. Não sendo estruturais, não são sustentáveis.

As políticas de democratização não devem apenas criar condições para que todos possam estudar, mas também assegurar igualdade de oportunidades, inclusive do ponto de vista qualitativo. Isso implica, 
Democratização, qualidade e crise da educação superior...

entre outras providências, a necessidade de ações e programas que preparem os jovens mais desfavorecidos para a dura competição pelo ingresso em bons cursos e carreiras socialmente valorizadas.

As disciplinas mais prestigiadas e que recebem mais generosos financiamentos, no atual momento da economia globalizada, são as de base técnica, como a biotecnologia, a biologia, a informática, a engenharia, a pesquisa médica, a eletrônica e outras que, com essas, compóem um campo que potencializa a competitividade de um país e das empresas. Essas disciplinas se desenvolvem com mais reconhecimento acadêmico e apoio financeiro, principalmente nas universidades públicas de referência e nas instituições privadas de alto custo, onde estão muito poucos dos estudantes beneficiados por programas de inclusão.

Todo indivíduo tem direito a uma educação de qualidade. $\mathrm{O}$ Estado, com a participação da sociedade, por princípio de justiça social e por estratégia de desenvolvimento nacional sustentável, tem o dever de assegurar a educação de qualidade como um bem social disponível a todos.

As relações entre o econômico e o simbólico (cultura, conhecimentos, ideologias, valores) implicam-se mutuamente. Essas relações determinam as hierarquias profissionais e dão forma e conteúdo aos poderes de diferentes tipos e níveis. Por outro lado, a privação dos recursos econômicos é correlativa da privação dos meios de aquisição de conhecimentos e do acesso aos bens culturais em geral.

$\mathrm{O}$ princípio da equidade implica um imperativo ético de diminuição ao máximo possível das desigualdades sociais. As políticas públicas de expansão de matrículas e inclusão social constituem um passo importante na luta pela superação das desigualdades, porém, isoladamente, são ainda insuficientes para romper as hierarquizações e diferenciações de uma sociedade dividida em excluídos e incluídos.

Particularmente para os jovens das classes pobres e abaixo da linha de pobreza, mas também para o país de modo geral, a expansão das matrículas apresenta um alto valor. Para esses jovens que, além das vulnerabilidades econômicas, em geral chegam ao nível superior com baixos repertórios educacionais e culturais, cada ano de escolaridade pode significar ganhos salariais, aumento no padrão de consumo, elevação da autoestima e das possibilidades de alcançarem 
melhores posições sociais. Porém, por muito importantes que sejam, as políticas públicas focadas na expansão das matrículas e na inclusão não rompem a estrutura verticalizada e desigual da sociedade. São positivas porque melhoram substancialmente as condições de vida de milhares de jovens tradicionalmente marginalizados e elevam sua autoestima, mas não alteram radicalmente o panorama social polarizado e estratificado.

Restrições econômicas e lacunas da formação precedente determinam as situações adversas dos jovens provenientes de setores marginalizados, que chegam à educação superior através de algum programa de inclusão social. De um lado, positivamente, esses programas criam oportunidades de estudos superiores a milhares de jovens de baixa renda; inscrevem-se nos processos que buscam maior equidade e contribuem para amenizar um pouco as adversidades educacionais de um bom número de jovens. Isto é muito valioso para quem dificilmente teria possibilidade de frequentar um curso superior, não fosse por meio de uma política pública. Por outro, não eliminam o vício fundamental da hierarquização social.

A implementação de políticas públicas focadas e emergenciais não extingue o caráter desigual da sociedade classista. As relações de seleção e diferenciação social se preservam, até mesmo se aprofundam, no interior do sistema educativo. A distribuição e a qualidade dos conhecimentos são muito variáveis e cumprem funções distintas na sociedade de classes. Não basta qualquer saber, não é indiferente qualquer curso e qualquer diploma. Mesmo entre os formados em cursos superiores se mantém uma hierarquia, de tons e graus variados, entre os formados em instituições de elite e os egressos de cursos de circuito popular.

Esse processo de seleção social reforçado na e pela educação superior encontra correspondência no aprofundamento de diferenciações e hierarquizaçôes institucionais, isto é, nas oposições entre instituições de elite, que ocupam o centro do sistema, e as instituições periféricas, geralmente dedicadas à absorção de matrículas de jovens de baixa renda.

Os jovens que escapam parcialmente dos constrangimentos mais duros da origem social e econômica precisam fazer um esforço muito maior que os estudantes procedentes de famílias de renda mais 
Democratização, qualidade e crise da educação superior...

alta para adquirir conhecimentos e técnicas bastante superiores aos que possuíam seus pais e que sirvam de condição básica para a disputa por empregos compatíveis com seus estudos. As lacunas de formação cultural e os constrangimentos econômicos constituem pesadas desvantagens nas disputas por melhores lugares nos cursos de maior apreço econômico-social e, de um modo geral, nas formaçóes sociais.

Os estudantes procedentes de setores sociais desfavorecidos, se conseguirem chegar à educação superior, inserem-se em cursos de menor prestígio social e econômico, em sua maioria da área de humanidades, que capacitam para postos de trabalho também pouco valorizados e escassamente criativos. Empregos com alta remuneração e boa reputação nesta sociedade modelada pela economia de mercado requerem os chamados "conhecimentos úteis", de base tecnológica, ou seja, aqueles conhecimentos e competências que geram lucro. Esses conhecimentos de elevado apreço e preço geralmente são produzidos e ensinados nas instituiçóes de ensino e pesquisa amplamente reconhecidas, que possuem boas estruturas físicas, atraem professores e pesquisadores de renome e estudantes bem selecionados e com boas condições de estudo. A expansão do sistema educacional é importante, mas são os grupos já favorecidos que melhor podem aproveitar as novas oportunidades criadas pelas transformações do ensino superior e da sociedade.

Os programas e as ações afirmativas praticados atualmente no Brasil criaram oportunidades de estudo concretas para cerca de 400 mil jovens, quase $10 \%$ do total de alunos de educação superior. Mas esses programas são focados e emergenciais. Atendem a uma parcela pequena da população e em cursos e instituições nem sempre de primeira linha. Por isso, não alteram significativamente os sentidos e estruturas do sistema de educação superior e muito menos da sociedade.

São, geralmente, desiguais as condiçôes de participação nos benefícios educativos e culturais, quando se comparam os beneficiários de programas de expansão e de açôes afirmativas e os jovens procedentes de setores privilegiados da sociedade. Poucos daqueles frequentam meios universitários com sólida ambiência acadêmica. Poucos daqueles têm uma formação em pesquisa e em ensino em áreas de alta competitividade, grande prestígio social e objetivamente calibradas 
com as rápidas e profundas evoluções na economia, na sociedade, nos conhecimentos e técnicas.

É inegável o grande valor social e humano dessas políticas e os benefícios que a inclusão traz à sociedade. Mas, assim como não alteram completamente as relaçóes estruturais verticalizadas da sociedade, também não conseguem transformar significativamente os modelos institucionais e pedagógicos. Não constroem outro tipo de instituição educativa de nível superior, nem quanto ao modelo organizacional e administrativo, nem relativamente aos currículos e métodos de ensino. Deixam intactos os modelos caracterizados por hierarquias e oposiçôes: instituiçóes públicas e privadas, grandes e pequenas, de pesquisa ou de ensino, de maior ou menor reconhecimento do ponto de vista da qualidade etc. Não produzem mudanças estruturais e tampouco colaboram para diminuir a crise de sentidos da universidade.

As hierarquias estão se aprofundando não só nos diferentes modelos organizacionais que constituem o sistema caótico de educação superior, mas também entre instituições do mesmo perfil e da mesma categoria administrativa. Por exemplo, as hierarquias e diferenciações se vão constituindo entre as universidades federais, igualmente entre as privadas ou entre as pequenas instituiçóes. Tampouco modificam as práticas pedagógicas, nem contribuem para construir novos currículos. Após a implementação dessas práticas, as instituições de educação superior continuam a oferecer os mesmos serviços educativos, com as mesmas orientações metodológicas e concepçôes curriculares, com a diferença de agora contarem com a presença de alguns novos alunos de segmentos sociais de mais baixa renda e um pequeno acréscimo de afrodescendentes, em geral oriundos da rede pública.

A universidade não está sabendo dizer a si mesma e à sociedade que tipo de instituição deve e é capaz de ser, para responder com alguma coerência e eficácia às múltiplas demandas desconexas e contraditórias que lhes são postas, num quadro histórico de rápidas transformações e obsolescência em todos os campos da ciência, da política e da economia, de crise dos valores e de tantas incertezas relativamente ao futuro.

Também o sistema permanece inalterado. Crescem ou ao menos se mantêm a diversificação de programas e cursos, a fragmentação das responsabilidades, a ociosidade, as diferenças regionais, a diferenciação 
Democratização, qualidade e crise da educação superior...

e a segmentação institucional. A pesquisa continua majoritariamente restrita às universidades públicas, cujas atividades se desenvolvem predominantemente em períodos diurnos. As instituições privadas, salvo as exceçôes conhecidas, se dedicam mais à absorção de matrículas e ao ensino em cursos de graduação, principalmente à noite, com foco na preparação de mão de obra para os empregos mais demandados pelo mercado.

A “democratização" centrada na expansão de matrículas e em ações afirmativas encontra limites nas universidades públicas, principalmente porque as estruturas de pesquisa são muito caras e os orçamentos públicos, bastante restritos.

As instituições públicas que são referências em pesquisa e ensino ou as instituições privadas de bom prestígio acadêmico são os destinos preferenciais dos jovens de maior renda. Jovens de baixa renda e beneficiários de políticas públicas de expansão de matrículas no setor privado, em geral oriundos da rede fundamental pública e com precário itinerário escolar, acabam ingressando, na maioria das vezes, em instituições meramente de ensino, em cursos de menor valor social e escassas atividades de iniciação científica.

Assim segue mantida a polarização entre instituições de referência, públicas ou privadas, e as de menor prestígio acadêmico. Essas diferenciações qualitativas produzem os prestígios hierarquizados dos diplomas e isso tem impactos importantes na competição pelos melhores postos no mercado de trabalho e na sociedade em geral.

Do ponto de vista do sistema e da atividade acadêmica, se vem fortalecendo a estratificação entre a graduação, restrita quase somente ao ensino e à capacitação profissional, e a pós-graduação, responsável pela pesquisa e formação de pesquisadores. Além dessa divisão de trabalho, surgem agora algumas instituições privadas dedicadas a formar as futuras elites para o mercado de alta competitividade.

\section{Em conclusão}

As reflexões anteriores permitem avançar esquematicamente algumas conclusões, algumas delas óbvias. São conclusões necessariamente provisórias e sujeitas a futuras revisões, pois as políticas brasileiras de expansão do acesso à educação superior são ainda muito recentes 
e não alcançam plenos consensos. O que segue retoma e reúne ideias anteriormente apresentadas:

- só faz sentido falar de "democratização da educação" a partir do princípio fundamental de educação como bem público, e não negócio;

- “democratização" não se restringe à expansão quantitativa; tem a ver também com qualidade pública e então com pertinência e relevância social; não havendo qualidade para todos, não se cumpre o princípio da equidade e não se diminuem as desigualdades sociais;

- as políticas públicas de "democratização" da educação superior devem propiciar mais e melhores oportunidades de acesso, mas sempre assegurando boas condições de permanência do estudante nos cursos;

- a "democratização" da educação superior não se esgota na questão da expansão do acesso e permanência; deveria estender-se aos currículos, à gestão e à democracia interna, efetivamente vivida nos distintos momentos e diferentes estruturas institucionais;

- a qualidade da educação superior não pode ser construída isoladamente, mas sim em conjunto com todo o sistema educativo e de ciência e tecnologia;

- é preciso melhorar e ampliar a educação fundamental, de modo a elevar a quantidade e a qualidade de concluintes no ensino médio; para tanto, é também fundamental ampliar e melhorar continuamente a formação de professores;

- é preciso ampliar e melhorar a infraestrutura geral da educação básica, pois a atual capacidade instalada é insuficiente para incorporar a totalidade de crianças e jovens que hoje estão fora das escolas;

- em matéria de investigação, inovação, ciência e tecnologia e de formação de investigadores, ao menos no caso brasileiro, é imprescindível que continue a haver uma forte participação do Estado e de suas instituições públicas; 
- há sérias dificuldades relativamente a uma expansão muito maior das matrículas, pois os recursos públicos são insuficientes e a capacidade e interesse das IES privadas em ampliar sua adesão ao PROUNI já estão perto de seu limite;

- ampliar a participação do Estado no provimento da educação superior de qualidade é muito importante, por diversas razões, inclusive porque a capacidade de financiamento privado é muito reduzida; cerca de $25 \%$ dos jovens das classes mais pobres não conseguiriam frequentar um curso superior, mesmo que esse fosse gratuito;

- é preciso reinstitucionalizar a educação superior: recuperar o sentido de instituição referenciada ao público e ao social, em vez de organização mercantil voltada ao interesse de lucro sem fim;

- as crises de diversos matizes que há na educação superior são internas - relativas às suas incapacidades pedagógicas, técnicas, políticas e administrativas - e externas, isto é, do contexto da evolução da informação e da ciência, em geral, e da sociedade da economia global;

- a expansão da educação superior com equidade depende muito de transformações estruturais e sustentáveis de âmbito geral, particularmente no sistema econômico;

- transformações radicais na educação superior não se separam de mudanças estruturais da sociedade humana, para as quais deverá concorrer a recuperação de valores fundamentais.

Recebido em janeiro de 2010 e aprovado em fevereiro de 2010.

\section{Referências}

DIAS SOBRINHO, J. Dilemas da educação superior no mundo globalizado: sociedade do conhecimento ou economia do conhecimento? São Paulo: Casa do Psicólogo, 2005.

DIAS SOBRINHO, J. Changes in Brazilian higher education and their effects on the enhancement of teaching (1995-2005). New 
Directions for Higher Education, San Francisco, n. 133, p. 91-101, 2006.

DIAS SOBRINHO, J. Calidad, pertinencia y relevancia: relación con el resto del sistema y la sociedad; responsabilidad social de la educación superior. In: Gazzola, A.L.; PIRES, S. (Ed.). Hacia una política regional de aseguramiento de la calidad en educación superior para América Latina y el Caribe. Caracas: UNESCO-IESALC, 2008. p. 15-55.

DIAS SOBRINHO, J.; BRITO, M.R.F. La educación superior en Brasil: principales tendencias y desafios. Avaliação, Sorocaba, v. 13, n. 2, p. 487- 507, jul. 2008.

DIAS SOBRINHO, J. Higher education: a public good, a State duty. In: Polak, E.E et al. (Ed.). Public responsability for higher education. Paris: UNESCO, 2009. p. 99-119

NEAVE, G. Educación superior: historia y política; estudios comparativos sobre la universidad contemporánea. Buenos Aires: Gedisa, 2001. 